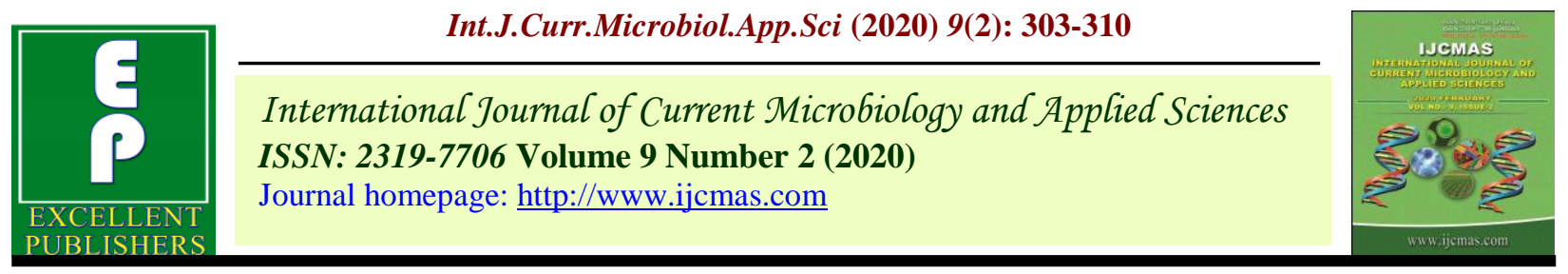

Original Research Article

https://doi.org/10.20546/ijcmas.2020.902.038

\title{
Bacteriological Profile and antibiogram of Gram Positive Cocci Isolated from Catheter Associated Urinary Tract Infection (CAUTI) in Intensive Care Units of a Tertiary Care Hospital
}

\author{
Sunil Kumar D Chavan ${ }^{1 *}$, T. Vineetha ${ }^{1}$, Chandrasekaran Kavita ${ }^{2}$ \\ ${ }^{1}$ Dept. of Microbiology, GMC, Kannur, Kerala, India \\ ${ }^{2}$ Periodontist and Implantologist, Kannur, Kerala, India \\ *Corresponding author
}

A B S T R A C T

Keywords

Intensive care units (ICU), Urinary tract infections (UTI), Catheter associated (CA), Multi drug resistant(MDR).

Article Info

Accepted:

05 January 2020

Available Online:

10 February 2020
Aim of the study was to isolate and characterize Gram positive cocci causing urinary tract infections in catheterized patients and to study the antimicrobial sensitivity pattern of the urinary isolates. Total of 100 catheterised patients in Intensive care units were analysed retrospectively in a period of 1 year from December 2017 to November 2018 to assess the urinary tract infections. Of 100 cases, 11 showed catheter associated urinary tract infections. Out of them 10 were Enterococcus spp, and 1 was Coagulase negative staphylococci. Isolates were multi drug resistant and showed sensitivity to Vancomycin, Linezolid, Teicoplanin. Infections were more with male sex, prolonged catheterization, old age and diabetes. High incidence of CAUTI was found in the first 2 weeks of catheterization. The antimicrobial susceptibility pattern confirmed that most of the urinary isolates in our environment are resistant to the commonly used antibiotics

\section{Introduction}

Catheter associated urinary tract infection is a leading cause of morbidity and mortality in hospitalized patients. When left in place for too long or used inappropriately, it is a hazard to the very patient that it is designed to protect. $^{18,21}$

According to 2009 International practice guidelines of Infectious Diseases Society of
America, CA-UTI in patients with indwelling urethral, indwelling suprapubic, or intermittent catheterization is defined by the presence of symptoms or signs compatible with UTI with no other identified source of infection along with $\geq 10^{3}$ colony forming units $(\mathrm{cfu} / \mathrm{ml})$ of $\geq 1$ bacterial species in a single catheter urine specimen or in a midstream voided urine specimen from a patient whose urethral, suprapubic or condom catheter has been removed within the 


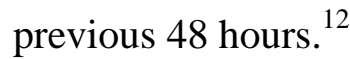

Patients in the Intensive care units are at high risk of device associated infection due to underlying conditions and impaired host defenses, surgery and invasive medical procedures. Indwelling urinary and central venous catheters are used commonly in the care of critically ill patients. Though important clinical benefits are provided by both types of devices, they are also the leading causes of nosocomial infection in the intensive care units. ${ }^{17}$

Approximately 97\% of UTI's in the ICU are associated with an indwelling urinary catheter. Because most patients admitted to ICU's have complications that are significant and are sicker than other patients, the effects of CA-UTI are more critical. ${ }^{6}$

CA-UTI are caused by a variety of pathogens, which includes Gram positive organisms like Enterococcus spp, CONS, Staphylococcus aureus. Up to $25 \%$ of patients who require a urinary catheter $\geq 7$ days develop Nosocomial bacteriuria with a daily risk of $5 \%$.Bacteriuria develops at an average rate of $3 \%$ to $10 \%$ per day of catheterization.

Many of these microorganisms belong to the patient's endogenous bowel flora but they can also be acquired from other patients or hospital personnel by cross-contamination or by exposure to contaminated solutions or nonsterile equipment. ${ }^{14}$

CAUTIs are a cause of concern because catheter- associated bacteriuria comprises a huge reservoir of resistant pathogens in the hospital environment. The epidemiology, frequency, microbiological spectrum and antimicrobial resistance patterns of microorganisms causing Device-Associated Infections vary among institutions and can change yearly.
Multidrug resistant pathogen infection are on the rise,which further complicates the management of these infections. Documented phenomena include the emergence of beta lactam and vancomycin resistance of Enterococci and Coagulase Negative Staphylococci. ${ }^{4}$

In healthy patients CA-UTI is often asymptomatic and is likely to resolve spontaneously with removal of the catheter. Infection persist occasionally and leads to complications such as prostatitis, epididymitis, cystitis, pyelonephritis and gram positive bacteremia particularly in high risk patients.

The last complication is serious since it is associated with a significant mortality but fortunately occurs in less than $1 \%$ of catheterized patient's.CA-UTI is the second most common cause of nosocomial blood stream infection. ${ }^{16}$

The vast majority of nosocomial UTI's occur in patients whose urinary tracts are currently or recently catheterized. The duration of catheterization is the most important risk factor for the development of CA-bacteriuria. Other risk factors for CA-bacteriuria include the lack of systemic antimicrobial therapy, female sex, meatal colonization with uropathogens, microbial colonization of the drainage bag, catheter insertion outside the operating room,catheter care violations like improper position of the drainage tube (above the level of the bladder or sagging below the level of collection bag),absence of use of a drip chamber, rapidly fatal underlying illness, older age, diabetes and elevated serum creatinine at the time of catheterization. ${ }^{11,18}$

Patients in the intensive care unit are at a higher risk of device-associated infection, due to their impaired host defences, underlying 
conditions, surgery, and invasive medical procedures. Central role in the pathogenesis of CAUTI is played by presence of a biofilm. CAUTIs are cause for concern because catheter-associated bacteriuria comprises a huge reservoir of resistant pathogens in the hospital environment and an important goal of health- care infection prevention programmes is prevention of infections attributable to these devices. ${ }^{1}$

Most episodes of bacteriuria in short term catheterized patients are caused by single organisms, mostly Enterococci and coagulase negative staphylococci. Enterococcus spp cause most of the infections.

Enterococcal species are among the predominant organisms responsible for causing CAUTI's. Fifteen to thirty percent of CAUTI's are caused by the Enterococcus species, especially Enterococcus faecalis and Enterococcus faecium and is therefore now considered as the third leading cause of hospital-acquired UTIs.

During CAUTIs, E.faecalis due to presence of a foreign body produce biofilms and results in persistent urinary tract infections. Biofilm formation by many enterococcal isolates and increasing resistance to antibiotics, including vancomycin pose significant challenges in treating enterococcal infections ${ }^{10,5}$

CA-UTI induced signs and symptoms include new onset of worsening of fever, rigors, malaise or lethargy, with no other identified cause, altered mental status, flank pain, tenderness of the costo- vertebral angle, acute hematuria, pelvic discomfort, and dysuria, urgent or frequent urination, or suprapubic pain or tenderness in those whose catheters have been removed. ${ }^{12}$

In patients with spinal cord injury (SCI),increased spasticity, autonomic dysreflexia or sense of unease are also compatible with CA-UTI. ${ }^{11}$

Although recommendations have been made to treat CAUTI's only when they are symptomatic, The CAUTI associated symptoms have not been clearly defined and unrelated to CAUTI, the presence of an indwelling urinary catheter alone can cause dysuria or urgency. ${ }^{20}$

Aim of the present study was to isolate and characterize Gram positive cocci causing urinary tract infections in catheterized patients and to study the antimicrobial sensitivity pattern of the urinary isolates.

\section{Materials and Methods}

100 in-patients of Intensive care units were analysed for a period of 1 year from December 2017 to November 2018 in Microbiology department at Academy of Medical Sciences, Pariyaram.

The sample included admitted patients with indwelling catheter of either sex and above 19 years of age of all intensive care units of Academy of Medical Sciences, Pariyaram.

The samples of Patients with confirmed urinary tract infection before catheterization, patients whose lab culture reported as mixed flora, urinary catheter tips, urine from catheter bags were excluded. Samples of urine after insertion of catheters was collected aseptically within 2 hours from the time of insertion for baseline urine cultures and microscopic examination. Thereafter urine cultures and urine analysis will be done on the 3rd day, 5th day, $7^{\text {th }}$, until Catheter is removed or Significant bacteriuria occurred on two consecutive cultures or patient is discharged, whichever comes early. Minimum three samples will be collected from each individual. 
Urine samples will be collected by aspirating urine from the Foley's catheter with sterile syringe with gauge 26 needle after disinfecting the catheter with $70 \%$ alcohol.

The samples are transported to the Microbiology laboratory immediately. If there is a delay of $>2$ hours, sample is refrigerated at $4^{\circ} \mathrm{C}^{9}$. Wet film microscopy and urine cultures will be done. ${ }^{8}$

A colony count of $\geq 10^{3} \mathrm{CFU} / \mathrm{ml}$ is considered positive. All the isolates were identified by standard procedures and biochemical tests and antimicrobial susceptibility test was done for pathogens isolated, by Kirby-Bauer disc diffusion technique.

The antibiotic discs used were from Himedia and the discs used were Ampicillin $(10 \mu \mathrm{g})$, Amoxyclav $(20 / 30 \mu \mathrm{g})$, Cephalexin $(30 \mu \mathrm{g})$, Cotrimoxazole $(1.24 / 23.75 \mu \mathrm{g})$ Nitrofurantoin $(300 \mu \mathrm{g}), \quad$ Tetracycline $(30 \mu \mathrm{g}), \quad$ Linezolid $(30 \mu \mathrm{g})$, Teicoplanin $(30 \mu \mathrm{g}), \quad$ Vancomycin $(30 \mu \mathrm{g})$, Novobiocin $(30 \mu \mathrm{g})$.
The antibiotic susceptibility was interpreted as sensitive, intermediate or resistant by comparing the observed zone of inhibition of the test organisms to the required zone size for the Standard strains as per CLSI Guidelines.

\section{Results and Discussion}

\section{Pearson Chi Square value: 32.47, p value<} 0.001

Total number of patients catheterized for one week were 43 , and the growth observed among this 43 was $1(2.3 \%)$, Total number of patients who were catheterized upto two weeks was 36 , among the 36 growth observed was $4(11.1 \%)$.

Out of the 15 patients catheterized for upto 3 weeks growth observed was 3 (20\%)., and 4 patients catheterized for 4 weeks and 2 patients catheterized for more than 4 weeks, half of them developed CA-UTI, that is 2 and 1 respectively.

Table.1 Number of samples obtained from the various ICU's

\begin{tabular}{|l|c|}
\hline I.C.U & NUMBER OF SAMPLES \\
\hline MICU & 56 \\
\hline SICU & 24 \\
\hline NSICU & 12 \\
\hline POICU & 7 \\
\hline CCU & 1 \\
\hline TOTAL & 100 \\
\hline
\end{tabular}

*Out of 100 samples collected, 56 samples were collected from MICU, 24 from SICU, 12 from NSICU, 7 from POICU and 1 from CCU respectively. 
Table.2 Association between the duration of catheterization and catheter- associated urinary tract infection.

\begin{tabular}{|l|c|c|}
\hline Duration of Catheterization & $\begin{array}{c}\text { Total no: of patients } \\
\text { catheterized }\end{array}$ & Growth \\
\hline 1 week & 43 & $1(2.3 \%)$ \\
\hline 2 week & 36 & $4(11.1 \%)$ \\
\hline 3 week & 15 & $3(20 \%)$ \\
\hline 4 week & 4 & $2(50 \%)$ \\
\hline More than 4 weeks & 2 & $1(50 \%)$ \\
\hline
\end{tabular}

Table.3 Percentage prevalence of catheter-associated urinary tract infections in the various icu 's of a tertiary care hospital.

\begin{tabular}{|l|l|}
\hline ICU & Culture Positive [\%] \\
\hline MICU & $\mathbf{5 ( 4 5 . 5 \% )}$ \\
\hline SICU & $\mathbf{3}(27 \%)$ \\
\hline NSICU & $\mathbf{2 ( 1 8 \% )}$ \\
\hline POICU & $\mathbf{1}(\mathbf{9 \%})$ \\
\hline CCU & $\mathbf{0 ( 0 \% )}$ \\
\hline TOTAL & $\mathbf{1 1}$ \\
\hline
\end{tabular}

Out of the 11 culture positive samples, 5 (45.5\%) were from MICU, 3 (27\%) were from SICU, 2 (18\%) were from NSICU, 1 (9\%) was from POICU. The highest percentage of growth was found in Medical ICU.

Table.4 Sex wise distribution of positive cultures.

\begin{tabular}{|l|c|c|}
\hline Sex & Culture Negative & Culture Positive \\
\hline Males & No: $(\boldsymbol{\%})$ & No: $(\boldsymbol{\%})$ \\
\hline Females & $\mathbf{3 7}(\mathbf{2 8 . 9})$ & $\mathbf{8}(\mathbf{1 7 . 7})$ \\
\hline
\end{tabular}

Table.5 Gram positive organisms isolated

\begin{tabular}{|l|l|}
\hline Gram positive organisms & number \\
\hline Enterococcus faecalis & $\mathbf{7}(\mathbf{6 3 . 6 \%})$ \\
\hline Enterococcus faecium & $\mathbf{3}(\mathbf{2 7 . 3 \% )}$ \\
\hline CONS & $1(\mathbf{9 . 1 \% )}$ \\
\hline TOTAL & 11 \\
\hline
\end{tabular}

Out of the 11 Gram positive cocci isolated,7( 63.6\%) were Enterococcus faecalis, 3(27.3\%) were Enterococcus faecium, and 1 CONS was isolated $(9.1 \%)$. 
Table.6 Sensitivity pattern of Enterococcus species

\begin{tabular}{|l|c|c|c|c|}
\hline & \multicolumn{2}{|c|}{$\boldsymbol{E}$.faecalis $(\boldsymbol{n}=7)$} & \multicolumn{2}{c|}{$\boldsymbol{E}$.faecium $(\boldsymbol{n}=\mathbf{3})$} \\
\hline DRUGS & $\mathrm{S}$ & $\mathrm{R}$ & $\mathrm{S}$ & $\mathrm{R}$ \\
\hline AMP & $\mathbf{1 ( 1 4 . 3 \% )}$ & $\mathbf{6 ( 8 5 . 7 \% )}$ & $\mathbf{1 ( 3 3 . 3 \% )}$ & $\mathbf{2 ( 6 6 . 7 \% )}$ \\
\hline AMC & $\mathbf{1 ( 1 4 . 3 \% )}$ & $\mathbf{6 ( 8 5 . 7 \% )}$ & $\mathbf{1 ( 3 3 . 3 \% )}$ & $\mathbf{2 ( 6 6 . 7 \% )}$ \\
\hline CEPH & $\mathbf{0 ( 0 \% )}$ & $\mathbf{7 ( 1 0 0 \% )}$ & $\mathbf{0 ( 0 \% )}$ & $\mathbf{3 ( 1 0 0 \% )}$ \\
\hline NIT & $\mathbf{2 ( 2 8 . 6 \% )}$ & $\mathbf{5 ( 7 1 . 4 \% )}$ & $\mathbf{0 ( 0 \% )}$ & $\mathbf{3 ( 1 0 0 \% )}$ \\
\hline COT & $\mathbf{0 ( 0 \% )}$ & $\mathbf{7 ( 1 0 0 \% )}$ & $\mathbf{0 ( 0 \% )}$ & $\mathbf{3 ( 1 0 0 \% )}$ \\
\hline TET & $\mathbf{4 ( 5 7 . 1 \% )}$ & $\mathbf{3 ( 4 2 . 9 \% )}$ & $\mathbf{2 ( 6 6 . 7 \% )}$ & $\mathbf{0 ( 0 \% )}$ \\
\hline LZ & $\mathbf{7 ( 1 0 0 \% )}$ & $\mathbf{0 ( 0 \% )}$ & $\mathbf{3 ( 1 0 0 \% )}$ & $\mathbf{0 ( 0 \% )}$ \\
\hline VA & $\mathbf{7 ( 1 0 0 \% )}$ & $\mathbf{0 ( 0 \% )}$ & $\mathbf{3 ( 1 0 0 \% )}$ & $\mathbf{0 ( 0 \% )}$ \\
\hline TEI & $\mathbf{7 ( 1 0 0 \% )}$ & $\mathbf{0 ( 0 \% )}$ & $\mathbf{3 ( 1 0 0 \% )}$ & $\mathbf{0 ( 0 \% )}$ \\
\hline
\end{tabular}

Pearson ChiSquare value: 4.209,p $<0.05$

Both E.faecalis and E. faecium showed 100\% resistance to Cephalexin and Cotrimoxazole. E.faecalis showed $57.1 \%$ and E. Faecium showed $66.7 \%$ sensitive to Tetracycline. Low percentage of sensitivity was shown by E.faecalis as well as E.faecium to Ampicillin $(14.3 \%$ and $33.3 \%$ respectively). All E.faecium was resistant to Nitrofurantoin whereas $E$ faecalis $(71.4 \%)$ was resistant to Nitrofurantoin. Both E.faecalis and E. faecium showed complete sensitivity to Vancomycin, Teicoplanin and Linezolid.

Urinary tract infections (UTIs) are commonly acquired in hospitals, representing 30\% -40\% of all nosocomial infections with an estimated prevalence of $1 \%$ to $10 \%$. Catheter-associated urinary tract infections is the most common nosocomial infection and accounts for bacteremia in 2 to $4 \%$ of patients and the case fatality associated with it is three times as high as nonbacteriuric patients. All age groups are affected by UTI and are diagnosed in both outpatients and hospitalized patients. It causes a serious burden on the socio economic life of individuals and leads to consumption of large population of all antibacterial drugs used in the world. Among catheterized patients the reported incidence of CAUTI ranges from as low as 5\% to as high as $73 \%$. In the present study, out of 100 cases studied, $11 \%$ developed CAUTI and high incidence of CAUTI was found in the first two weeks of catheterization. This result is comparable with that of a study by Danchaivijitr et al where one hundred and one patients met the inclusion criteria and the incidence of CAUTI was $73.3 \%$ and high incidence of CAUTI was found in the first two weeks of catheterization.

None of the episodes of CAUTI in our study was associated with nosocomial bacteremia and yeast was isolated as the commonest uropathogen which is again similar to the study by Danchaivijitr et al., Like this study prolonged catheterization was identified as a risk factor in the present study also. ${ }^{15}$ The predominant organism isolated in our present study was Enterococcus spp, (10 in numbers - 90.9\%), out of which $70 \%$ were Enteroccus faecalis and $30 \%$ were Enterococcus faecium. Studies done by Ho Lee et al who evaluated 1,315 patients at medical and surgical ICUs, out of which 61 people developed CAUTI and Enterococcus spp was seen in $30.6 \%$ patients. Similarly in a prospective study in a medical intensive care unit including 137 consecutive catheterised patients by Tissot et al 17\% of the pathogens that caused CAUTI was Enterococcus spp. The percentage of CONS isolated in our study was only $9.1 \%$, whereas 
a study done by Thombare et al isolated $6.06 \%$ of CONS responsible for causing CAUTI. The CONS isolated in our study showed sensitivity to Nitrofurantoin, Cephalexin, Amoxycillin-Clavalunic acid, Clindamycin, Vancomycin, Linezolid, Teicoplanin and Rifamycin, a zone of more than $25 \mathrm{~mm}$ was observed to Cefoxitin, hence it was not Methicillin resistant CONS. In the study by Thombare et $\mathrm{al}^{4}$ sensitivity to the drugs were Ampicillin (25\%), Gentamicin (50\%), Cefoxitin (100\%), Vancomycin (100\%), and Nitrofurantoin $(50 \%)$.

All health care associated UTI are caused by instrumentation of the urinary tract.The incidence was more in males and risk factors identified were prolonged catheterisation,old age and diabetes mellitus. High incidence of CAUTI was found in the first 2 weeks of catheterisation. Longer duration of catheterization increases the chances of CAUTI. The antimicrobial susceptibility pattern confirmed that most of the urinary isolates in our environment are resistant to the commonly used antibiotics.

Hospital acquired CAUTI is often due to multi drug resistant strains which require higher antibiotics and these strains may spread to other patients. Effective infection prevention measures should be in place to reduce the prevalence of nosocomial UTIs. Better management of urinary catheter is to be explored and implemented.

\section{References}

Nicolle LE. Catheter associated urinary tract infections. Crit Care. 2014;1:4-1.

Hossain MD, Ahsan S, Kabir MS. Antibiotic resistance patterns of uropathogens isolated from catheterized and noncatheterized patients in Dhaka, Bangladesh. Tzu Chi Med J. 2014;26(3):127-31.
Shahidul Kabir,Sunjukta Ahsan MDH. Antibiotic resistance patterns of uropathogens isolated from cathterized and noncatheterized patients in Dhaka, Bangladesh. Elsevier. 26(2):1-5.

V.R.Thombare,Neelam K.Jaitly IB. Microbiological evaluation of catheter associated urinary tract infection in a tertiary care hospital. Int J Biol Health Sci. 2013 Jan;1(2):01-10.

Guiton PS, Hannan TJ, Ford B, Caparon MG, Hultgren SJ. Enterococcus faecalis overcomes foreignbody-mediated inflammation to establish urinary tract infections. Infect Immun. 2013;81(1):329-39.

Lee JH, Kim SW, Yoon BI, Ha U, Sohn DW, Cho Y-H. Factors that affect nosocomial catheter-associated urinary tract infection in intensive care units: 2year experience at a single center. Korean J Urol. 2013;54(1):59-65.

Edward M.Schaeffer AJS. CAMPBELLWALSH UROLOGY. 10th ed. United states of America: Elsevier Saunders; 2012. 272-326 p.

Inan A, Ozgultekin A, Akcay SS, Engin DO, Turan G, Ceran N, et al., Alterations in Bacterial Spectrum and Increasing Resistance Rates in Isolated Microorganisms from DeviceAssociated Infections in an Intensive Care Unit of a Teaching Hospital in Istanbul(2004-2010). Jpn J Infect Dis. 2012;65(2):146-51.

Marra AR, Sampaio Camargo TZ, Gonçalves $\mathrm{P}$, Sogayar AMCB, Moura Jr DF, Guastelli LR, et al., Preventing catheterassociated urinary tract infection in the zero-tolerance era. Am J Infect Control. 2011;39(10):817-22.

Guiton PS, Hung CS, Hancock LE, Caparon MG, Hultgren SJ. Enterococcal biofilm formation and virulence in an optimized murine model of foreign bodyassociated urinary tract infections. 
Infect Immun. 2010;78(10):4166-75.

Raphael Dolin,John E. Bennett GLM. Mandell,Douglas and Bennett's Principles and Practice of Infectious Diseases. 7th ed. United States of America: Churchill Livingstone; 2010. 957-985 p.

Hooton TM, Bradley SF, Cardenas DD, Colgan R, Geerlings SE, Rice JC, et al., Diagnosis, prevention, and treatment of catheter-associated urinary tract infection in adults: 2009 International Clinical Practice Guidelines from the Infectious Diseases Society of America. Clin Infect Dis. 2010;50(5):625-63.

Nina.E.Tokoff-Rubin,Ramzi S.Cotran RHR. Brenner \& Rector's The Kidney. 8th ed. Saunders Elsevier; 2008. 1203-1231 p.

Taiwo SS, Aderounmu AOA. Catheter associated urinary tract infection: aetiologic agents and antimicrobial susceptibility pattern in Ladoke Akintola University Teaching Hospital, Osogbo, Nigeria. Afr J Biomed Res [Internet]. 2006 [cited 2014 Oct 4];9(3). Available from: http://www.ajol.info/index.php/ajbr/arti cle/view/48897

Danchaivijitr S, Dhiraputra C, Cherdrungsi R, Jintanothaitavorn D, Srihapol N. Catheter-associated urinary tract infection. J Med Assoc Thai. 2005;88(suppl 10):26-30.

Trautner BW, Darouiche RO. Catheterassociated infections: pathogenesis affects prevention. Arch Intern Med. 2004;164(8):842-50.

Saint S, Savel RH, Matthay MA. Enhancing the safety of critically ill patients by reducing urinary and central venous catheter-related infections. Am J Respir Crit Care Med. 2002;165(11):1475-9.

Maki DG, Tambyah PA. Engineering out the risk for infection with urinary catheters. Emerg Infect Dis. 2001;7(2):342.

Tissot E, Limat S, Cornette C, Capellier G. Risk factors for catheter-associated bacteriuria in a medical intensive care unit. Eur J Clin Microbiol Infect Dis. 2001;20(4):260-2.

Tambyah PA, Maki DG. Catheter-associated urinary tract infection is rarely symptomatic: a prospective study of 1497 catheterized patients. Arch Intern Med. 2000;160(5):678-82.

Febre N, Silva V, Medeiros EAS, Wey SB, Colombo AL, Fischman O. Microbiological characteristics of yeasts isolated from urinary tracts of intensive care unit patients undergoing urinary catheterization. J Clin Microbiol. 1999;37(5):1584-6.

Saint S, Lipsky BA. Preventing catheterrelated bacteriuria: should we? Can we? How? Arch Intern Med. 1999;159(8):800-8.

Stamm WE. Catheter-associated urinary tract infections: epidemiology, pathogenesis, and prevention. Am J Med. 1991;91(3):S65-71.

\section{How to cite this article:}

Sunil Kumar D Chavan, T. Vineetha, Chandrasekaran Kavita. 2020. Bacteriological Profile and antibiogram of Gram Positive Cocci Isolated from Catheter Associated Urinary Tract Infection (CAUTI) in Intensive Care Units of a Tertiary Care Hospital. Int.J.Curr.Microbiol.App.Sci. 9(02): 303-310. doi: https://doi.org/10.20546/ijcmas.2020.902.038 